\title{
Remote-sensing estimation of dissolved inorganic nitrogen concentration in the Bohai Sea using band combinations derived from MODIS data
}

\author{
Xiang Yu, Huapeng Yi, Xiangyang Liu, Yebao Wang, Xin Liu \& Hua Zhang
}

To cite this article: Xiang Yu, Huapeng Yi, Xiangyang Liu, Yebao Wang, Xin Liu \& Hua Zhang (2016) Remote-sensing estimation of dissolved inorganic nitrogen concentration in the Bohai Sea using band combinations derived from MODIS data, International Journal of Remote Sensing, 37:2, 327-340, DOI: 10.1080/01431161.2015.1125555

To link to this article: http://dx.doi.org/10.1080/01431161.2015.1125555

Published online: 12 Jan 2016.

Submit your article to this journal $\llbracket$

Џ Article views: 95

View related articles $₫$

View Crossmark data $\nearrow$ 


\title{
Remote-sensing estimation of dissolved inorganic nitrogen concentration in the Bohai Sea using band combinations derived from MODIS data
}

\author{
Xiang $\mathrm{Yu}^{\mathrm{a}, \mathrm{b}}$, Huapeng $\mathrm{Yi}^{\mathrm{c}}$, Xiangyang Liu ${ }^{\mathrm{a}, \mathrm{b}}$, Yebao Wang ${ }^{\mathrm{a}, \mathrm{b}}$, Xin Liu ${ }^{\mathrm{a}}$ and Hua Zhang \\ aYantai Institute of Coastal Zone Research Chinese Academy of Sciences, Yantai, China; bUniversity of \\ Chinese Academy of Sciences, Beijing, China; Institute of Geography and Planning, Ludong University, \\ Yantai, China
}

\begin{abstract}
Remote sensing has been widely used for water quality monitoring, but most monitoring studies have only focused on a few water quality variables, such as chlorophyll- $a$, turbidity, and total suspended solids, which have typically been considered optically active variables. Remote sensing presents a challenge in estimating dissolved inorganic nitrogen (DIN) concentration in water. DIN in inland waters and estuaries had been estimated from remotely sensed observations. However, remote-sensing estimation of DIN in seawater over a large area had not yet been performed. Moreover, the bands used to estimate DIN in water were limited to 4 or 7 anterior bands of Moderate Resolution Imaging Spectroradiometer (MODIS) data at high spatial resolution rather than high spectral resolution. In this study, we attempted to establish a model to estimate DIN concentration in the Bohai Sea using band combinations derived from all the visible/nearinfrared (Vis-NIR) bands of MODIS data. The results showed that regional multiple stepwise regression analysis (MLSR) yields a highly significant positive relationship between DIN concentration and certain remotely sensed combination variables. The modelling yielded higher accuracy for DIN concentration estimation in the Bohai Sea compared with previous studies. DIN concentration values showed a clear spatial variability, being high in coastal waters and relatively low further out. These results strongly suggest that the modelling demonstrates advantages for estimating DIN concentration in the Bohai Sea and has major potential for universal application in DIN concentration estimation in other waters.
\end{abstract}

\section{ARTICLE HISTORY}

Received 17 June 2015

Accepted 19 November 2015

\section{Introduction}

Because of the increasing discharge of nutrients into water from various pollution sources, the quality of surface water has deteriorated and eutrophication has become a severe pollution problem in many countries over recent decades (Kondratyev and Pozdnyakov 1998; He et al. 2008; Li et al. 2009; Smith, Tilman, and Nekola 1999; 
Sherwood and Qualls 2001; Gao, Gao, and Chen 2011). Numerous studies have suggested that DIN is one of the main nutrients limiting eutrophication of aquatic ecosystems (e.g. Edmondson 1970; Dillon and Rigler 1974; Vollenweider 1976; Schindler 1977; Tyrrell 1999; Guildford and Hecky 2000). Monitoring DIN changes is important for controlling eutrophication in lakes, reservoirs, and other water bodies (Seker et al. 2003).

The various in situ techniques currently used for measuring and monitoring DIN concentrations in water are time consuming and do not provide a synoptic view of the water body within the landscape (Bilge et al. 2003; He et al. 2008). Fortunately, remote sensing can provide a tool for DIN monitoring because it has been used successfully to monitor other water quality variables, such as temperature (e.g. Alcântara et al. 2010), chlorophyll-a (e.g. Yacobi et al. 2011; Bresciani et al. 2011), turbidity (e.g. Güttler, Simona, and Francis 2013), and total suspended solids (e.g. Bistani 2009), with a higher precision observed for lakes and reservoirs (Chen et al. 2015; Mao et al. 2012; Wu et al. 2010) around the world (Bistani 2009). However, most studies on water quality remote sensing have mainly focused on optically active variables (He et al. 2008): few have focused on non-optically active compounds such as dissolved inorganic nitrogen (DIN) (e.g. Xu et al. 2011, 2012, 2013), total phosphorus (TP) (e.g. Wu et al. 2010; Santaella and Campos 2008), total nitrogen (TN) (e.g. He et al. 2008), dissolved oxygen (DO) (e.g. Xie et al. 2007), chemical oxygen demand (COD) (e.g. Wang et al. 2004; Yang et al. 2011), or biochemical oxygen demand (BOD) (e.g. Wang et al. 2004). Although remote sensing has the potential to estimate water quality variables, it presents a challenge in estimating DIN concentration. In theory, remote-sensing estimation of DIN concentration is difficult using a physical model. However, DIN concentration may be highly correlated with that of chl- $a$, chromophoric dissolved organic matter (CDOM), or total suspended solids (TSS) (Chen et al. 2015; Heiskary and Wilson 2005; Li and Xiao 2011). Chl-a, CDOM, and TSS have direct optical properties and spectral characteristics and can be estimated by remote sensing. In the Bohai Sea it was found that the correlation coefficient value between DIN and chl- $a$ concentrations was 0.92 in flush time, and they were highly significantly correlated at the $p<0.01$ significance level (Shen et al. 2004). These findings suggest that concentrations of optically active compounds strongly correlated with surface reflectance, such as chl- $a$, might serve as a proxy for DIN concentration. Therefore, the logical deduction, which is the assumption of this study, is that there is a correlation between remote-sensing observations and DIN concentration in seawater, in the form of the reflectance.

To date, attempts to estimate DIN concentration in water bodies have achieved some success. Using the correlations between ground-truth data and combinations of spectral bands from remotely sensed data, spectral indices have been developed that can be used to estimate nitrogen content. Combinations of spectral bands from 'Beijing-1' micro-satellite data were applied to estimation of DIN concentrations in Sheyang estuary (Xu et al. 2013). Similarly, combinations of spectral bands from MODIS data were applied respectively to estimate DIN concentrations in Haizhou Bay and Sheyang estuary (Xu et al. 2011, 2012). However, these bands were selected with an emphasis on high spatial resolution rather than high spectral resolution.

Ellyson and Ecker (2005) demonstrated that a principal component analysis of more than 20,000 remote sensed pixels can be used in a regression analysis to accurately predict DIN levels in Casey Lake, at three separate times during the summer of 2004. In a 
study by He et al. (2008), a water quality retrieval model was established and was used to analyse total nitrogen, ammonia nitrogen, and nitrate nitrogen using Landsat 5 Thematic Mapper (TM) data and multiple regression algorithms. According to the results of case studies (e.g. Ellyson and Ecker 2005; He et al. 2008), lake DIN was estimated from remotely sensed observations, primarily using the simple individual band ratio or their natural logarithm and statistical regression method based on field DIN data and the spectral reflectance. However, when a water body is very large, has spatial variability in water quality, and has obvious concentration gradients between its constituent parts, statistical modelling based on the band ratio and other simple methods cannot reflect the spatial heterogeneity of DIN; thus, multivariate statistical modelling may be an effective method to estimate DIN concentration. In addition, most previous studies were carried out on seriously polluted inland water bodies and estuaries. Large marine areas, such as the Bohai Sea, have not been taken into account but they continue to represent an important part of water quality management.

This study selected spectral resolution in regard to the extraction of slightly refined spectral indices for DIN concentration estimation in the Bohai Sea. Band combinations significantly related to DIN concentrations derived from all visible/near-infrared (Vis-NIR) bands of MODIS data were taken into account in multivariate statistical modelling. The objectives of this study were as follows: (1) to develop an empirical remote-sensing model to estimate DIN concentrations in the Bohai Sea using band combinations derived from all Vis-NIR bands of MODIS data and multivariate statistical modelling techniques; and (2) to characterize the spatial variability of DIN concentration in the Bohai Sea.

\section{Materials and methods}

\subsection{Study area}

The Bohai Sea is a semi-enclosed Chinese water body, with a huge amount of domestic sewage and industrial waste water discharged into it every day, some of it via rivers. According to a recent report on water quality in rivers emptying into Chinese coastal seas, all 11 routinely monitored rivers emptying into the Bohai Sea were equal to or lower than Level IV Environmental Quality Standards for Surface Water (GB3838-2002). Five of the 11 rivers exceeded Level V standards (SOA 2013). Thus, monitoring DIN changes is important in regard to controlling eutrophication in the Bohai Sea. To the best of our knowledge, this is the first study of DIN concentration estimation based on remote sensing in the aqueous environment of the Bohai Sea.

\subsection{Field measurements}

\subsubsection{Sampling sites}

In this study, 120 water-sampling sites were established, as showed in Figure 1. The water was sampled only once at each sampling site, between 25 August and 2 September 2014. The samples were obtained at a depth of 0-0.2 m. Each sampling site was geographically located using a global positioning system (Garmin, GPSMAP 60 


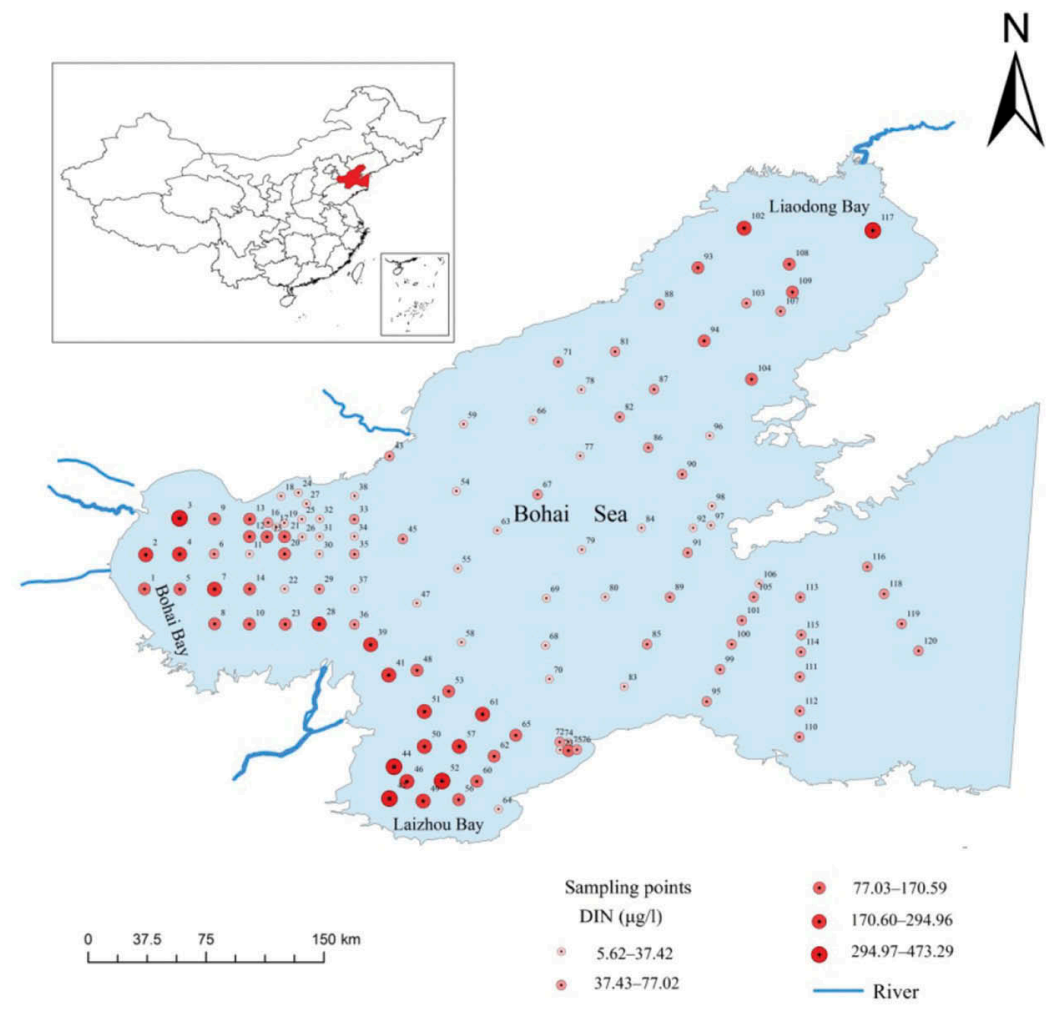

Figure 1. Location of the Bohai Sea in China, and the spatial distribution of DIN concentration at the sampling sites.

CSx) with a precision of 3-6 $\mathrm{m}$ (Chen et al. 2008). After sampling, water samples were immediately acid-preserved in a portable refrigerator set at a temperature of $4^{\circ} \mathrm{C}$.

\subsubsection{Laboratory analysis}

The water samples were transported to the laboratory for DIN concentration analysis. Nitrite was determined by the naphthalene ethylenediamine spectrophotometry method; ammonium was measured by the hypobromite oxidation method; and nitrate was measured by the cadmium column reduction method (GB17378.4-2007). Outliers of DIN concentration were eliminated on the basis of normal distribution to prepare data for the next step of modelling.

\subsection{Remotely sensed image preprocessing}

The remotely sensed data used in this study were acquired from the MODIS-Aqua Level2 image on 27 August 2014 (http://ladsweb.nascom.nasa.gov/data/). The MODIS radiance data were atmospherically corrected to retrieve apparent surface reflectance using fast line-of-sight atmospheric analysis of spectral hypercubes (FLAASH), which is a MODTRAN-4-based correction algorithm available with the ENVI software package (Exelis Visual Information Solutions, Boulder, CO) (Matthew et al. 2000). Atmospheric 
Table 1. Summary of 24 variables evaluated for the prediction model for surface DIN.

\begin{tabular}{|c|c|c|c|c|c|}
\hline Variable & Algorithm & Variable & Algorithm & Variable & Algorithm \\
\hline $\begin{array}{l}F_{1}(i) \\
F_{2}(i) \\
F_{3}(i) \\
F_{4}(i) \\
F_{5}(i) \\
F_{6}(i) \\
F_{7}(i, j) \\
F_{8}(i, j)\end{array}$ & $\begin{array}{l}R_{i} \\
R_{i}^{2} \\
R_{i}^{3} \\
e^{R i} \\
R_{i}{ }^{1 / 2} \\
\operatorname{Ln} R_{i} \\
R_{i}-R_{j} \\
R_{i} \times R_{j} \\
\end{array}$ & $\begin{array}{l}F_{9}(i, j) \\
F_{10}(i, j) \\
F_{11}(i, j) \\
F_{12}(i, j) \\
F_{13}(i, j) \\
F_{14}(i, j) \\
F_{15}(i, j) \\
F_{16}(i, j)\end{array}$ & $\begin{array}{l}R_{i} R_{j} \\
\left(R_{i}-R_{j}\right) /\left(R_{i}+R_{j}\right) \\
\left(R_{i}+R_{j}\right) /\left(R_{i}-R_{j}\right) \\
\left(R_{i} \times R_{j}\right) /\left(R_{i}+R_{j}\right) \\
\left(R_{i} \times R_{j}\right) /\left(R_{i}-R_{j}\right) \\
\left(R_{i}+R_{j}\right) /\left(R_{i} \times R_{j}\right) \\
\left(R_{i}-R_{j}\right) /\left(R_{i} \times R_{j}\right) \\
\left.\left(R_{i}-R_{j}\right)\right)^{3}\end{array}$ & $\begin{array}{l}F_{17}(i, j) \\
F_{18}(i, j) \\
F_{19}(i, j) \\
F_{20}(i, j) \\
F_{21}(i, j) \\
F_{22}(i, j) \\
F_{23}(i, j) \\
F_{24}(i, j)\end{array}$ & $\begin{array}{l}\left(R_{i} \times R_{j}\right)^{3} \\
\left(R_{i} R_{j}\right)^{3} \\
\left(\left(R_{i}-R_{j}\right) /\left(R_{i}+R_{j}\right)\right)^{3} \\
\left(\left(R_{i}+R_{j}\right) /\left(R_{i}-R_{j}\right)\right)^{3} \\
\left(\left(R_{i} \times R_{j}\right) /\left(R_{i}+R_{j}\right)\right)^{3} \\
\left(\left(R_{i} \times R_{j}\right) /\left(R_{i}-R_{j}\right)\right)^{3} \\
\left(\left(R_{i}+R_{j}\right) /\left(R_{i} \times R_{j}\right)\right)^{3} \\
\left(\left(R_{i}-R_{j}\right) /\left(R_{i} \times R_{j}\right)\right)^{3}\end{array}$ \\
\hline
\end{tabular}

correction for the image was based on a mid-latitude summer atmospheric model and a rural aerosol model. The retrieved reflectance images were georeferenced using the Georeference MODIS module available with the ENVI software. Images of spatial resolution $500 \mathrm{~m}$ (bands 3-7) and $1000 \mathrm{~m}$ (bands 8-26) were resampled to images of spatial resolution $250 \mathrm{~m}$ (bans 1-2). The Bohai Sea image was subset by the boundary map in ArcGIS 10.0 software.

\subsection{Algorithm development for the estimation of DIN concentration and accuracy assessment}

An algorithm based on field data and statistical analyses was selected as the modelling approach to estimate DIN concentration. Multiple stepwise linear regression (MLSR) between remote-sensing reflectance and DIN in situ concentrations was completed for a single band, band ratio, natural logarithm of the band, and certain other band combinations, as shown in Table 1. Accuracy assessment based on statistical errors was performed for the obtained regressions. Field sampling was performed to test and validate the developed algorithm.

The performance of the DIN estimation equation was evaluated using scatter plots and regression statistics, as well as the coefficient of determination $\left(R^{2}\right)$, root mean square error (RMSE), and residual prediction deviation (RPD), defined as the ratio of standard deviation (SD) to RMSE, was employed as a sign of model stability (Nduwamungu et al. 2009). Chang et al. (2001) defined three categories of model according to RPD values: (1) category A (RPD > 2) - accurate prediction of a given property; (2) category B $(1.4<$ RPD < 2.0) - an intermediate class; (3) category C (RPD < 1.4) - no predictive ability.

\section{Results and discussion}

\subsection{DIN concentration of water samples and its relationship with remotely sensed variables}

\subsubsection{DIN concentration of water samples}

Table 2 summarizes the statistics of DIN concentration in water samples from Bohailaizhou Bay, Liaodong Bay, and the inner sea. For the 120 water samples from the Bohai Sea, DIN concentration ranged from 5.26 to $473.29 \mu \mathrm{g} \mathrm{I}^{-1}$ with an average of $89.53 \mu \mathrm{g} \mathrm{I}^{-1}$, SD of $91.18 \mu \mathrm{g} \mathrm{I}^{-1}$, and variation coefficient of $101.84 \%$. For the 51 water samples from Bohai-laizhou Bay, DIN concentration ranged from 5.62 to $397.25 \mu \mathrm{g} \mathrm{I}^{-1}$ with an average of 
Table 2. Summary statistics of DIN concentration of water samples in the Bohai Sea.

\begin{tabular}{lccccc}
\hline Region & Mean $\left(\mu \mathrm{g} \mathrm{I}^{-1}\right)$ & $\operatorname{Min}\left(\mu \mathrm{g} \mathrm{I}^{-1}\right)$ & $\operatorname{Max}\left(\mu \mathrm{g} \mathrm{I}^{-1}\right)$ & $S D\left(\mu \mathrm{g} \mathrm{I}^{-1}\right)$ & $C V\left(\mu \mathrm{g} \mathrm{I}^{-1}\right)$ \\
\hline Bohai-laizhou Bay & 144.44 & 5.62 & 397.25 & 102.77 & 0.7115 \\
Liaodong Bay & 141.42 & 53.94 & 473.29 & 127.48 & 0.9014 \\
Inner sea & 37.81 & 26.42 & 83.48 & 7.80 & 0.2063 \\
Total & 89.53 & 5.62 & 473.29 & 91.18 & 1.0184 \\
\hline
\end{tabular}

144.44 $\mathrm{g} \mathrm{I}^{-1}$, SD of $102.77 \mu \mathrm{g} \mathrm{I}^{-1}$, and variation coefficient of $71.15 \%$. For the 10 water samples from Liaodong Bay, DIN concentration ranged from 53.94 to $473.29 \mathrm{\mu g} \mathrm{I}^{-1}$ with an average of $141.43 \mu \mathrm{g} \mathrm{I}^{-1}$, SD of $127.48 \mathrm{\mu g} \mathrm{I}^{-1}$, and variation coefficient of $90.14 \%$. For the 59 water samples from the the inner sea, DIN concentration ranged from 26.42 to $83.48 \mathrm{\mu g} \mathrm{I}^{-1}$ with an average of $37.81 \mu \mathrm{g} \mathrm{I}^{-1}$, SD of $7.80 \mu \mathrm{g} \mathrm{I}^{-1}$, and variation coefficient of $20.63 \%$.

The statistical values in Table 2 show that the mean, SD, and variation coefficient of DIN concentration in Bohai-laizhou and Liaodong bays were significantly higher than those of the inner sea. Moreover, the mean values of DIN concentration in Bohailaizhou Bay were approximately 3.82-fold those in the inner sea, with a SD of 5.34-fold and variation coefficient of 3.45 -fold. Similarly, the mean values of DIN concentration in Liaodong Bay were approximately 3.74-fold those in the inner sea, with a SD of 5.34fold and variation coefficient of 4.37-fold. Therefore, there may be certain limitations in the estimation of DIN concentration using statistical regression models based on the 120 sampling points over the entire Bohai Sea. Except for modelling of the entire Bohai Sea, regional statistical modelling was used. Based on the DIN in situ concentrations and the 24 spectral variables shown in Table 1, Bohai-laizhou Bay, Liaodong Bay, and the inner sea were modelled separately using the same modelling method that was used for the entire Bohai Sea.

\subsubsection{Relationship between DIN concentration and remotely sensed variables}

The correlation analysis results shown in Table 3 indicate that DIN concentration and 24 remotely sensed variables are highly significantly $(p<0.01)$ correlated in the 120 sampling sites throughout the Bohai Sea. Single variables, including $F_{1}(i), F_{2}(i), F_{3}(i), F_{4}$ (i), $F_{5}(i)$, and $F_{6}(i)$, contained 11 bands highly significantly $(p<0.01)$ correlated to DIN concentration. Bands 4 and 12 performed well in the correlation analysis. All maximum values of correlation coefficient occurred at bands 4 and 12. The correlation coefficient between $F_{3}(4)$ and DIN concentration was 0.61 . This result is similar to a that of a previous study (Xu et al. 2011), which showed that DIN concentration was positively correlated to the green bands (bands 4 and 12). Similarly, band 1 performed well with a correlation coefficient of 0.50 , which was a result of the weak absorption of yellow seawater substances in the red band (Lei, Pan, and Tao 2009). Moreover, multiple variables, from $F_{7}(i, j)$ to $F_{24}(i, j)$, contained dozens or even hundreds of band combinations highly significantly $(p<0.01$ ) correlated to DIN concentration. The correlation coefficient between the above variables and DIN concentration exceeded 0.7 . Therefore, the single band or its derived band combinations, significantly correlated with DIN concentration, can be used to estimate DIN concentration in the Bohai Sea through statistical modelling. 
Table 3. Correlation coefficient and statistical significance between observed DIN concentration and remotely sensed variables.

\begin{tabular}{lccccc}
\hline & & & & & \\
Remotely sensed variable & Min & Max & Mean & $\begin{array}{c}\text { Number of variables } \\
(p<0.01)\end{array}$ \\
\hline$F_{1}(i)$ & -0.42 & 0.57 & 0.1519 & 0.29442 & 11 \\
$F_{2}(i)$ & -0.43 & 0.60 & 0.1479 & 0.30297 & 11 \\
$F_{3}(i)$ & -0.43 & 0.61 & 0.1475 & 0.30614 & 11 \\
$F_{4}(i)$ & -0.42 & 0.57 & 0.1525 & 0.29725 & 11 \\
$F_{5}(i)$ & -0.40 & 0.56 & 0.1559 & 0.28669 & 11 \\
$F_{6}(i)$ & 0.01 & 0.56 & 0.2417 & 0.19551 & 11 \\
$F_{7}(i, j)$ & -0.71 & 0.72 & 0.0752 & 0.40040 & 152 \\
$F_{8}(i, j)$ & -0.42 & 0.58 & 0.0812 & 0.31070 & 131 \\
$F_{9}(i, j)$ & -0.71 & 0.68 & 0.0451 & 0.34751 & 90 \\
$F_{10}(i, j)$ & -0.71 & 0.68 & 0.0958 & 0.33416 & 123 \\
$F_{17}(i, j)$ & -0.63 & 0.73 & -0.1229 & 0.35245 & 134 \\
$F_{12}(i, j)$ & -0.41 & 0.57 & 0.0837 & 0.29251 & 118 \\
$F_{13}(i, j)$ & -0.63 & 0.74 & -0.1164 & 0.34567 & 120 \\
$F_{14}(i, j)$ & -0.54 & 0.01 & -0.2256 & 0.16519 & 66 \\
$F_{15}(i, j)$ & -0.73 & 0.68 & 0.0673 & 0.31831 & 62 \\
$F_{16}(i, j)$ & -0.73 & 0.72 & 0.0686 & 0.39704 & 152 \\
$F_{17}(i, j)$ & -0.43 & 0.61 & 0.0801 & 0.30714 & 119 \\
$F_{18}(i, j)$ & -0.71 & 0.68 & 0.0396 & 0.35030 & 91 \\
$F_{19}(i, j)$ & -0.74 & 0.71 & 0.0914 & 0.32628 & 124 \\
$F_{20}(i, j)$ & -0.60 & 0.71 & -0.1217 & 0.33005 & 131 \\
$F_{21}(i, j)$ & -0.03 & 0.61 & 0.2070 & 0.21483 & 69 \\
$F_{22}(i, j)$ & -0.62 & 0.73 & -0.0939 & 0.33732 & 78 \\
$F_{23}(i, j)$ & -0.54 & 0.06 & -0.2043 & 0.15424 & 64 \\
$F_{24}(i, j)$ & -0.74 & 0.72 & 0.0509 & 0.29627 & 63 \\
\hline & & & & \\
\end{tabular}

\subsection{Estimation model and validation}

The simple correlation coefficient was calculated by considering only the correlation between two variables rather than the effect of the other variables. Therefore, MLSR was further used to quantitatively measure the relationship between DIN concentration and the various remotely sensed variables. First, MLSR estimation models of DIN concentration were established based on DIN concentrations at $75 \%$ of the random sample sites in the Bohai Sea and 24 remotely sensed band combination indicators. After comparison of $R^{2}$, RMSE, and RPD for the different regression models, the best regression models with the least RMSE for predicting DIN concentration in the Bohai Sea were obtained (Table 4, Figure 2).

To test whether the prediction models described above were reliable and applicable in the estimation of DIN concentration, independent data sets of the remaining samples

Table 4. Statistics of best model performances for predicting DIN concentration.

\begin{tabular}{|c|c|c|c|c|c|c|c|}
\hline \multirow[b]{2}{*}{ Region } & \multirow[b]{2}{*}{ Regression equation } & \multicolumn{3}{|c|}{ Prediction models } & \multicolumn{3}{|c|}{ Validation models } \\
\hline & & $R^{2}$ & $\begin{array}{l}R M S E \\
\left(\mu \mathrm{g} \mathrm{I}^{-1}\right)\end{array}$ & $R P D$ & $R^{2}$ & $\begin{array}{c}R M S E \\
\left(\mu \mathrm{g} \mathrm{I}^{-1}\right)\end{array}$ & $R P D$ \\
\hline Entire Bohai Sea & $\begin{array}{l}\mathrm{DIN}=-69.562+0.008 \times F_{20}(8,10)+0.044 \times F_{20} \\
(1,20)\end{array}$ & 0.60 & 57.49 & 1.58 & 0.68 & 49.23 & 1.74 \\
\hline Bohai-laizhou Bay & $\begin{array}{l}\mathrm{DIN}=-4.514+0.011 \times F_{20}(8,10)-0.159 \times F_{20} \\
(3,4)+0.008 \times F_{20}(14,21)-0.001 \times F_{20}(12,15)\end{array}$ & 0.85 & 39.43 & $2.58^{*}$ & 0.82 & 41.12 & $2.27^{*}$ \\
\hline Liaodong Bay & $\mathrm{DIN}=30.960+0.0000009199 \times F_{20}(11,12)$ & 0.98 & 17.04 & $7.10^{*}$ & 0.99 & 7.18 & $21.98^{*}$ \\
\hline Inner sea & $\begin{array}{l}\mathrm{DIN}=13.532+0.160 \times F_{20}(1,5)+0.007 \times F_{20} \\
(8,19)\end{array}$ & 0.77 & 3.74 & $2.07^{*}$ & 0.79 & 2.35 & $2.05^{*}$ \\
\hline
\end{tabular}

*model in category $\mathrm{A}$. 

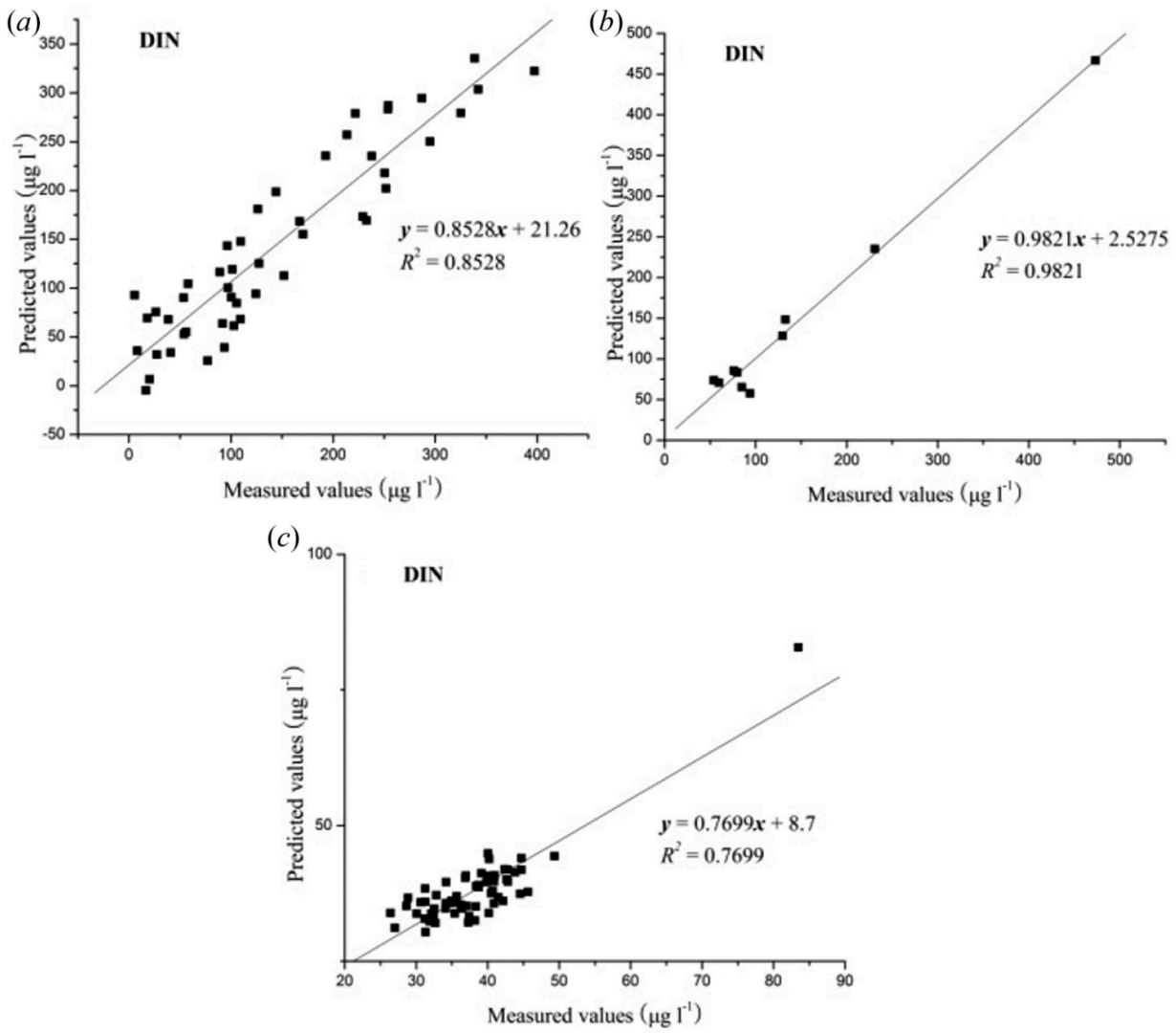

Figure 2. Comparison of observed and predicted DIN concentration in Bohai-laizhou Bay (a), Liaodong Bay (b), and the inner sea (c) based on MLSR calibration models.

(about $25 \%$ of all samples) were used to validate their respective performance (Table 4, Figure 3).

The DIN concentration in Bohai-laizhou Bay was well estimated by the MLSR model based on $F_{20}(i, j)\left(R^{2}=0.85\right.$, RMSE $=39.43$, RPD $\left.=2.58\right)$, and the validation model was stable $\left(R^{2}=0.82\right.$, RMSE $\left.=41.12, \mathrm{RPD}=2.27\right)$. It was evident that DIN concentration in Bohai-laizhou Bay was well evaluated using MLSR models developed with $F_{20}(i, j)$. Similarly, estimation models for DIN concentration in Liaodong Bay $\left(R^{2}=0.98\right.$, RMSE $=17.04, \operatorname{RPD}=7.10)$ and the inner sea $\left(R^{2}=0.77, \operatorname{RMSE}=3.73, \operatorname{RPD}=2.07\right)$ performed well, and the validation models remained stable with $R^{2}$ of 0.99 and 0.79 , RMSE of 7.18 and 2.35, and RPD of 21.98 and 2.05, respectively. These results indicate that the DIN concentration in Bohai-laizhou Bay, Liaodong Bay, and the inner sea can be well estimated using MLSR models developed with $F_{20}(i, j)$. $F_{20}(i, j)$ performed well in the development of sensitive waveband combinations for estimating DIN concentration. However, the DIN concentration of the entire Bohai Sea could not be estimated by MLSR developed with $F_{20}(i, j)\left(R^{2}=0.60\right.$, RMSE $=57.49$, RPD $\left.=1.58\right)$. Regional statistical modelling was proved to be effective in estimating non-uniformly distributed DIN concentration in seawater over a large area. Eqs. 1, 2, and 3 show the best multiple regression models $\left(R^{2}>0.77\right)$, which had higher prediction accuracy for DIN 

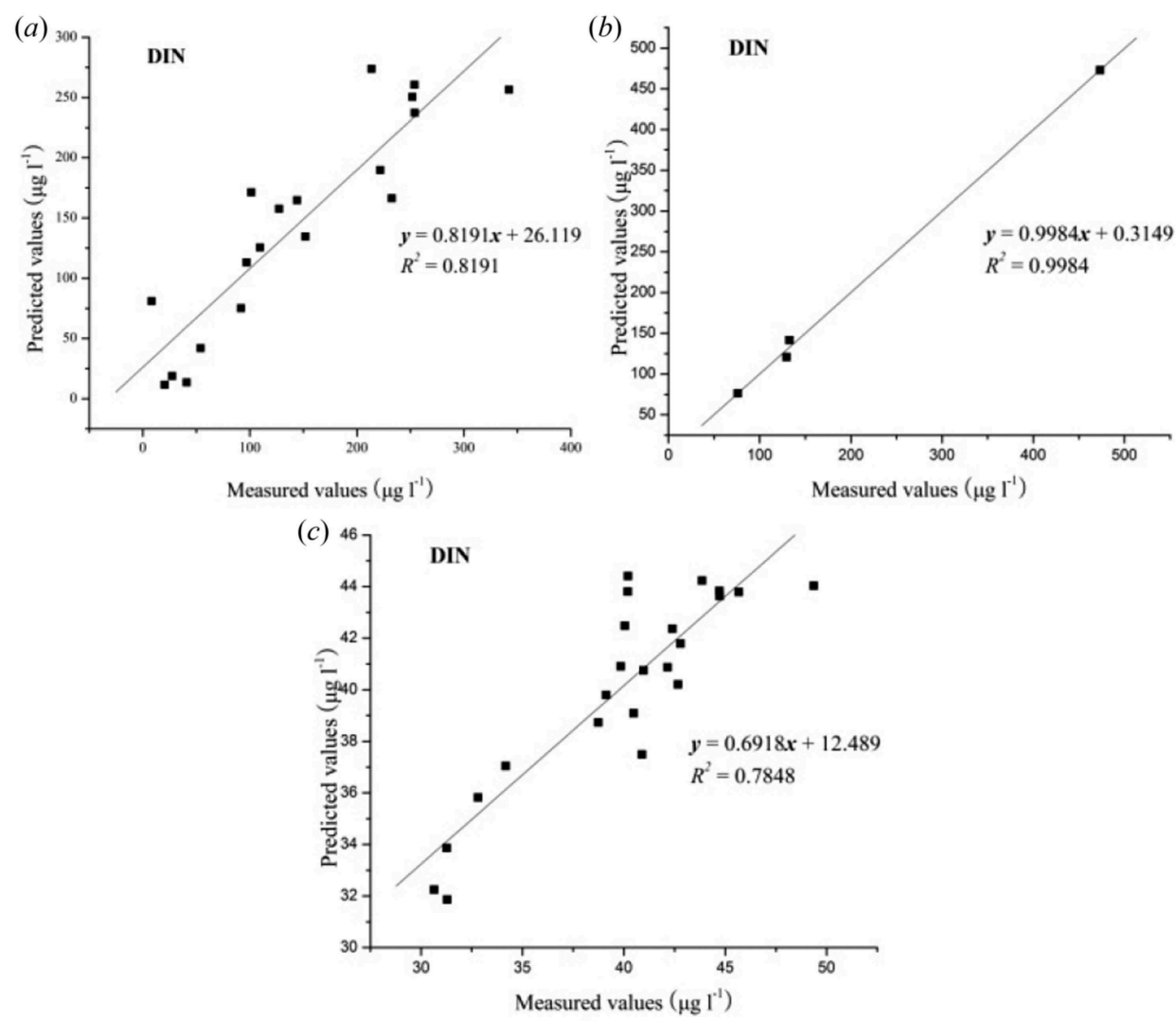

Figure 3. Comparison of observed and predicted DIN concentration in Bohai-laizhou Bay (a), Liaodong Bay (b), and the inner sea (c) based on MLSR validation models.

concentration estimation compared with previous studies $\left(R^{2}=0.64, R^{2}=0.72\right)$ (Xu et al. 2011, 2012):

$$
\begin{gathered}
\mathrm{DIN}=-4.514+0.011 \times F_{20}(8,10)-0.159 \times F_{20}(3,4)+0.008 \times F_{20}(14,21) \\
-0.001 \times F_{20}(12,15), \\
\operatorname{DIN}=30.960+0.0000009199 \times F_{20}(11,12), \\
\mathrm{DIN}=13.532+0.160 \times F_{20}(1,5)+0.007 \times F_{20}(8,19) .
\end{gathered}
$$

\subsection{Spatial characteristics of DIN}

Equations 1, 2, and 3 were subsequently used to empirically predict the DIN concentration of Bohai-laizhou Bay, Liaodong Bay, and the inner sea, respectively (Figure 4).

For the entire Bohai Sea, estimation values of DIN concentration ranged from 25.90 to $603.35 \mu \mathrm{g} \mathrm{I}^{-1}$ with an average of $105.46 \mu \mathrm{g} \mathrm{I}^{-1}$, SD of $125.64 \mu \mathrm{g} \mathrm{I}^{-1}$, and variation coefficient of $119.00 \%$. Estimation values of DIN concentration in Bohai-laizhou Bay ranged from 34.09 to $484.68 \mu \mathrm{g} \mathrm{I}^{-1}$ with an average of $262.46 \mu \mathrm{g} \mathrm{I}^{-1}$, SD of $177.94 \mu \mathrm{g}$ 

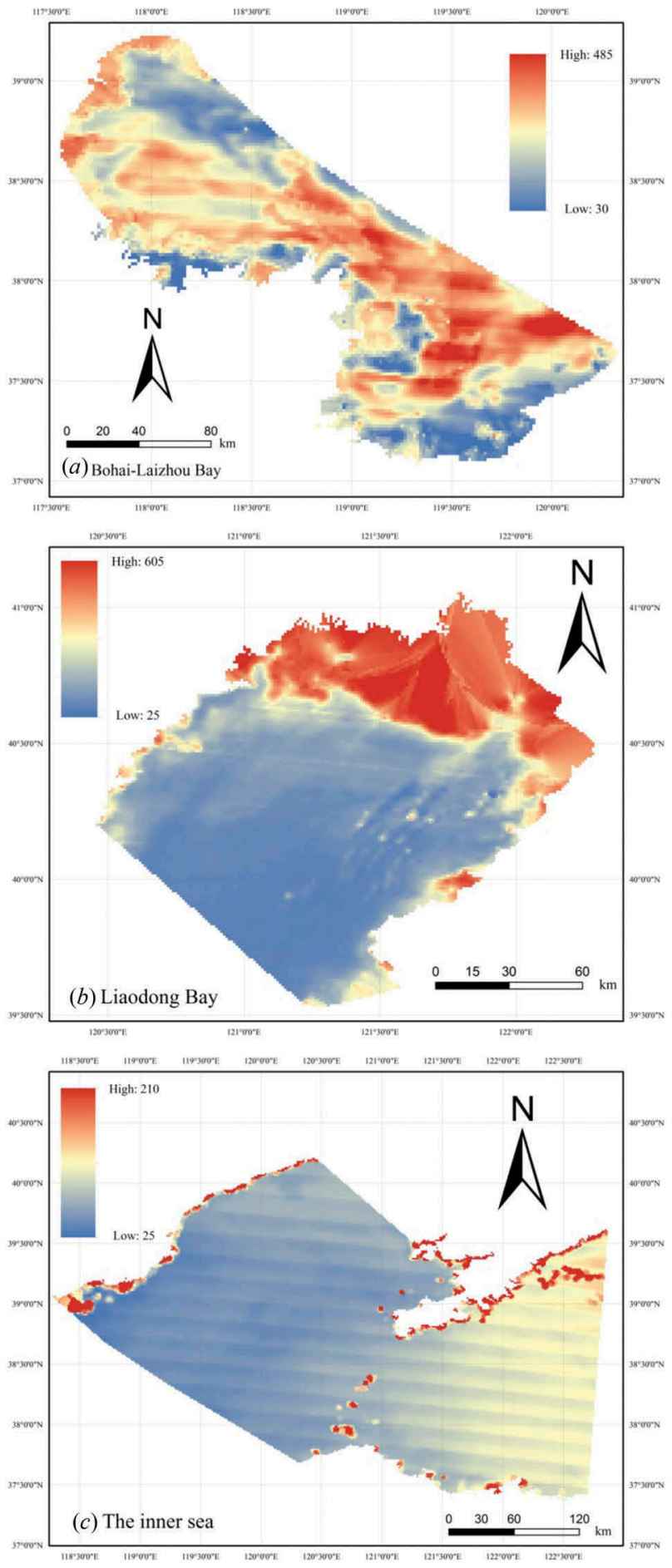

Figure 4. Predicted DIN concentration $\left(\mu \mathrm{g} \mathrm{I}^{-1}\right)$ from MODIS image in the Bohai Sea. 
$\mathrm{I}^{-1}$, and variation coefficient of $67.80 \%$. Estimation values of DIN concentration in Liaodong Bay ranged from 29.67 to $603.35 \mu \mathrm{g} \mathrm{I}{ }^{-1}$ with an average of $141.43 \mu \mathrm{g} \mathrm{I}^{-1}$, SD of $204.06 \mathrm{~m} \mathrm{I} \mathrm{I}^{-1}$, and variation coefficient of $79.00 \%$. Estimation values of DIN concentration in the inner sea ranged from 25.90 to $209.18 \mu \mathrm{g} \mathrm{I}^{-1}$ with an average of $34.67 \mu \mathrm{g}$ $\mathrm{I}^{-1}$, SD of $9.44 \mu \mathrm{g} \mathrm{I}^{-1}$, and variation coefficient of $27.22 \%$. From the spatial distribution of DIN concentration shown in Figure 4, it will be observed that DIN concentration in coastal areas was markedly higher than that in the inner sea. DIN concentration was highest in Bohai-laizhou Bay. The DIN concentration in Liaodong Bay was lower than that in Bohai-laizhou Bay, and was the lowest in the inner sea. The non-uniform distribution pattern is mainly a result of the discharge of nutrients into the water from various pollution sources, such as the rivers Yellow, Haihe, Luanhe, Liaohe, and others.

\section{Conclusions}

In this study, we investigated the possibility of establishing a model to estimate DIN concentration in the Bohai Sea from hyperspectral satellite imagery using band combinations and multivariate statistical modelling techniques. The principal conclusions can be summarized as follows:

(1) DIN, which is considered a non-optically active compound in water, does not possess direct optical properties and spectral characteristics. However, DIN concentration may be highly correlated with chl-a concentration, the CDOM, or the TSS value, and chl- $a$, CDOM, and TSS have direct optical properties and spectral characteristics that can be estimated by remote sensing. DIN concentration can be estimated through the correlation equation using the reflectance of remote sensing.

(2) MODIS hyperspectral satellite imagery can be used to estimate DIN concentration in seawater over a large area. Correlation and regression analysis showed a highly significant positive relationship between DIN concentration and certain remotely sensed variables. The model validation results showed that the estimation modelling had high accuracy in regard to DIN concentration estimation in the Bohai Sea.

(3) DIN concentration values showed a clear spatial variability, being high in coastal areas and relatively low in the inner sea. Bohai Bay, Laizhou Bay, and Liaodong Bay had the highest DIN concentrations. Regional statistical modelling was shown to be effective in estimating non-uniformly distributed DIN concentration in seawater over a large area.

(4) These results strongly suggest that the band combinations and regional multivariate statistical modeling techniques used here demonstrate advantages in estimating DIN concentration in the Bohai Sea. However, further testing must be performed to validate the universal applicability of these modelling techniques for DIN concentration estimation in other seas.

\section{Disclosure statement}

No potential conflict of interest was reported by the authors. 


\section{Funding}

This work was jointly supported by the Key Research Programme of the Chinese Academy of Sciences [grant number NSFC41371483], [grant number KZZD-EW-14]; the Shandong Province Natural Science Fund Committee [grant number ZR2011DL013].

\section{References}

Alcântara, E. H., J. L. Stech, J. A. Lorenzzetti, M. P. Bonnet, X. Casamitjana, A. T. Assireu, and E. M. L. Novo de. 2010. "Remote Sensing of Water Surface Temperature and Heat Flux over a Tropical Hydroelectric Reservoir." Remote Sensing of Environment 114 (11): 2651-2665. doi:10.1016/j. rse.2010.06.002.

Bilge, F., B. Yazici, T. Dogeroglu, and C. Ayday. 2003. "Statistical Evaluation of Remotely Sensed Data for Water Quality Monitoring." International Journal Remote Sens 24 (24): 5317-5326. doi:10.1080/0143116031000156828.

Bistani, L. F. C. 2009. "Identifying Total Phosphorus Spectral Signal in a Tropical Estuary Lagoon using a Hyperspectral Sensor and Its Application to Water Quality Modeling." Doctoral thesis, Civil Engineering, University of Putro Rico, Mayagüez Campus.

Bresciani, M., D. Stroppiana, D. Odermatt, G. Morabito, and C. Giardino. 2011. "Assessing Remotely Sensed Chlorophyll- $A$ for the Implementation of the Water Framework Directive in European Perialpine Lakes." Sciences Total Environment 409 (17): 3083-3091. doi:10.1016/j. scitotenv.2011.05.001.

Chang, C. W., D. W. Laird, M. J. Mausbach, and C. R. Hurburgh. 2001. "Near-Infrared Reflectance Spectroscopy Principal Components Regression Analyses of Soil Properties." Soil Science Society of America Journal 6: 480-490. doi:10.2136/sssaj2001.652480x.

Chen, L., C. H. Tan, S. J. Kao, and T. S. Wang. 2008. "Improvement of Remote Monitoring on Water Quality in a Subtropical Reservoir by Incorporating Grammatical Evolution with Parallel Genetic Algorithms into Satellite Imagery." Water Research 42: 296-306. doi:10.1016/j. watres.2007.07.014.

Chen, S. S., L. S. Han, X. Z. Chen, D. Li, L. Sun, and Y. Li. 2015. "Estimating Wide Range Total Suspended Solids Concentrations from MODIS 250-M Imageries: An Improved Method." ISPRS Journal PHOTOGRAMM 99: 58-69. doi:10.1016/j.isprsjprs.2014.10.006.

Dillon, P. J., and F. H. Rigler. 1974. "The Phosphorus-Chlorophyll Relationship in Lakes." Limnology and Oceanography 19: 767-773. doi:10.4319/lo.1974.19.5.0767.

Edmondson, W. T. 1970. "Phosphorus, Nitrogen and Algae in Lake Washington after Diversion of Sewage." Science 169: 690-691. doi:10.1126/science.169.3946.690.

Ellyson, K., and M. D. Ecker. 2005. "Remote Sensing Calibration of Casey Lake and Silver Lake." American Journal Undergrad Researcher 4 (1): 19-25.

Gao, Y., J. Gao, and J. Chen. 2011. "Spatial Variation of Surface Soil Available Phosphorous and Its Relation with Environmental Factors in the Lake Chaohu Watershed." International Journal Environment Researcher Public Health 8 (8): 3299-3317. doi:10.3390/ijerph8083299.

Guildford, S. J., and R. E. Hecky. 2000. "Total Nitrogen, Total Phosphorus, and Nutrient Limitation in Lakes and Oceans: Is There a Common Relationship?." Limnology and Oceanography 45: 12131223. doi:10.4319/lo.2000.45.6.1213.

Güttler, F. N., N. Simona, and G. Francis. 2013. "Turbidity Retrieval and Monitoring of Danube Delta Waters Using Multi-Sensor Optical Remote Sensing Data: An Integrated View from the Delta Plain Lakes to the Western-Northwestern Black Sea Coastal Zone. Remote Sens." Environment 132: 86-101.

He, W., S. Chen, X. Liu, and J. Chen. 2008. "Water Quality Monitoring in Slightly-Polluted Inland Water Body through Remote Sensing-A Case Study in Guanting Reservoir, Beijing, China." Frontiers Environment Sciences Engineering China 2 (2): 163-171. doi:10.1007/s11783-008-0027-7.

Heiskary, S., and B. Wilson. 2005. Minnesota Lake Water Quality: Developing Nutrient Criteria. 3rd ed. St Paul, MN: Minnesota Pollution Control Agency. 
Kondratyev, K., and D. V. Pozdnyakov. 1998. "Water Quality Remote Sensing in the Visible Spectrum." International Journal Remote Sens 19 (5): 957-979. doi:10.1080/014311698215810.

Lei, H., D. L. Pan, and B. Y. Tao. 2009. "The Spectral Absorption and Distribution Characteristics of CDOM in the Typical Waters of the East China Sea." Acta Oceanologica Sinica 31 (2): 57-62.

$\mathrm{Li}, \mathrm{K}$., and P. Xiao. 2011. "Temporal and Spatial Distribution of Chlorophyll-A Concentration and Its Relationships with TN, TP Concentrations in Lake Chaohu." Journal Biologic 28 (1): 53-56.

Li, M., Y. J. Wu, Z. L. Yu, G. P. Sheng, and H. Q. Yu. 2009. "Enhanced Nitrogen and Phosphorus Removal from Eutrophic Lake Water by Ipomoea Aquatica with Lowenergy Ion Implantation." Water Research 43: 1247-1256. doi:10.1016/j.watres.2008.12.013.

Mao, Z. H., J. Y. Chen, D. L. Pan, B. Y. Tao, and Q. K. Zhu. 2012. "A Regional Remote Sensing Algorithm for Total Suspended Matter in the East China Sea." Remote Sensing of Environment 124: 819-831. doi:10.1016/j.rse.2012.06.014.

Matthew, M. W., S. M. Adler-Golden, A. Berk, S. C. Richtsmeier, R. Y. Levine, and L. S. Bernstein et al. 2000. "Status of Atmospheric Correction Using a MODTRAN4-Based Algorithm." SPIE Proceedings, Algorithms for Multispectral, Hyperspectral, and Ultraspectral Imagery VI 4049:199207).

Nduwamungu, C., N. Ziadi, L. E. Parent, G. F. Tremblay, and L. Thuries. 2009. “Opportunities For, and Limitations Of, near Infrared Reflectance Spectroscopy Applications in Soil Analysis: A Review." Canadian Journal of Soil Science 89 (5): 531-541. doi:10.4141/CJSS08076.

Santaella, F. G., and L. Campos. 2008. "Monitoring Phosphorus Content in a Tropical Estuary Lagoon Using an Hyperspectral Sensor and its Application to Water Quality Modeling." Accessed 22 Sep 2011. gers.uprm.edu/pdfs/report_sjbay.pdf

Schindler, D. W. 1977. "The Evolution of Phosphorus Limitation in Lakes." Science 195: 260-266. doi:10.1126/science.195.4275.260.

Seker, D. Z., C. Goksel, S. Kabdasli, N. Musaoglu, and S. Kaya. 2003. "Investigation of Coastal Morphological Changes Due to River Basin Characteristics by Means of Remote Sensing and GIS Techniques." Water Sciences Technological 48 (10): 135-142.

Shen, Y. L., H. Zhang, X. Ma, D. W. Kong, and L. N. Ma. 2004. "The Influence for the Ocean Primary Yield - Power (Chlorofucine) with the Change of Inorganic Nitrogen and Reactive Phosphate in the Bohai Ocean Gulf." Environment Monitoring Chinese 20 (1): 52-54.

Sherwood, L. J., and R. G. Qualls. 2001. "Stability of Phosphorus within a Wetland Soil following Ferric Chloride Treatment to Control Eutrophication." Environment Sciences Technological 35: 4126-4131. doi:10.1021/es0106366.

Smith, V. H., G. D. Tilman, and J. C. Nekola. 1999. “Eutrophication: Impacts of Excess Nutrient Inputs on Freshwater, Marine, and Terrestrial Ecosystem." Environment Pollution 100: 179-196. doi:10.1016/S0269-7491(99)00091-3.

SOA. 2013. Marine Environmental Information, Section 8 (Total 21). People's Republic of China: State Oceanic Administration.

Tyrrell, T. 1999. "The Relative Influences of Nitrogen and Phosphorus on Oceanic Primary Production." Nature 400: 525-531. doi:10.1038/22941.

Vollenweider, R. A. 1976. "Advances in Defining Critical Loading Levels of Phosphorus in Lake Eutrophication." Memory Dell'istituto Ital Idrobiol 33: 53-83.

Wang, Y. P., H. Xia, J. M. Fu, and G. Y. Sheng. 2004. "Water Quality Change in Reservoirs of Shenzhen, China: Detection Using LANDSAT/TM Data." Sciences Total Environment 328 (1-3): 195-206. doi:10.1016/j.scitotenv.2004.02.020.

Wu, C., J. Wu, J. Qi, L. Zhang, H. Huang, L. Lou, and Y. Chen. 2010. "Empirical Estimation of Total Phosphorus Concentration in the Mainstream of the Qiantang River in China Using Landsat TM Data." International Journal Remote Sens 31 (9): 2309-2324. doi:10.1080/01431160902973873.

Xie, H., X. H. Tong, Y. L. Qiu, H. E. Zhang, Y. L. Zhang, and J. F. Zhao. 2007. "Monitoring Model and Temporal Spatial Changes of Dissolved Oxygen Based on Remote Sensing: A Case Study in Huangpu River." Spectroscopy and Spectral Analysis 27 (18): 1574-1579.

Xu, Y., C. C. Cheng, Y. Zhang, and D. Zhang. 2012. "Research on Monitoring the Concentration of Dissolved Inorganic Nitrogen and Dissolved Inorganic Phosphorus near Sheyang Estuary Based on MODIS." Marine Sciences Bulletin 31 (6): 700-706. 
Xu, Y., C. C. Cheng, Y. Zhang, and D. Zhang. 2013. "Determine Concentrations of Nitrogen and Phosphorus in Estuary with Satellite Image." Oceanologia Et Limnologia Sinaca 44 (6): $1486-1492$.

Xu, Y., Y. Zhang, H. Q. Chen, and D. Zhang. 2011. "Study on Dissolved Inorganic Nitrogen Monitoring Based on MODIS Imaging for Haizhou Bay." Advances in Marine Science 29 (1): 73-80.

Yacobi, Y. Z., W. J. Moses, S. Kaganovsky, B. Sulimani, B. C. Leavitt, and A. A. Gitelson. 2011. "NIRRed Reflectance-Based Algorithms for Chlorophyll-A Estimation in Mesotrophic Inland and Coastal Waters: Lake Kinneret Case Study." Water Research 45: 2428-2436. doi:10.1016/j. watres.2011.02.002.

Yang, B., Y. P. Liu, F. P. Ou, and M. H. Yuan. 2011. "Temporal and Spatial Analysis of COD Concentration in East Dongting Lake by Using of Remotely Sensed Data." Procedia Environment Sciences 10: 2703-2708. doi:10.1016/j.proenv.2011.09.420. 